\title{
MODELO DE CINCO FATORES DE RISCO: PRECIFICANDO CARTEIRAS SETORIAIS NO MERCADO ACIONÁRIO BRASILEIRO
}

\author{
FIVE RISK FACTORS MODEL: PRICING SECTORAL PORTFOLIOS IN THE \\ BRAZILIAN STOCK MARKET
}

\author{
MATHEUS DUARTE VALENTE VIEIRA \\ Mestre em Administração pelo IAG/PUC-Rio. Auditor Fiscal de \\ Tributos do Município de Cuiabá. Endereço: Rua Marquês de São \\ Vicente, 225 / Gávea | 22453-900 | Rio de Janeiro/RJ / Brasil. \\ E-mail: vieiramatheus001@gmail.com
}

\section{VINICIUS MOTHÉ MAIA}

Doutorando do IAG/PUC-Rio. Professor de Contabilidade da FACC/UFRJ. Endereço: Endereço: Av. Pasteur 250 - sala 242 / Urca / 22290-240 / Rio de Janeiro/RJ / Brasil.

E-mail: viniciusmothemaia@yahoo.com.br

\section{MARCELO CABÚS KLOTZLE}

Doutor em Economia. Professor do Quadro Principal IAG/PUC-Rio. Endereço: Rua Marquês de São Vicente, 225 / Gávea | 22453-900 | Rio de Janeiro/RJ / Brasil.

E-mail: klotzle@iag.puc-rio.br

\section{ANTONIO CARLOS FIGUEIREDO}

Doutor em Economia. Professor do Quadro Principal IAG/PUC-Rio. Endereço: Rua Marquês de São Vicente, 225 / Gávea | 22453-900 | Rio de Janeiro/RJ / Brasil.

E-mail: figueiredo@iag.puc-rio.br

\section{RESUMO}

O prêmio de risco dos ativos é a variável central dos modelos de finanças que buscam estimar o custo do capital das empresas, custo esse empregado, por exemplo, na avaliação do preço das ações. São diversos os modelos empregados para o cálculo do prêmio de risco. Os modelos de Fama e French são amplamente conhecidos e difundidos. Em 2015, Fama e French apresentaram um novo modelo com a introdução de dois novos prêmios de risco. Devido à relevância do tema e à possibilidade de conseguir novas informações a partir desse novo modelo, o objetivo do trabalho é realizar um estudo no mercado de ações brasileiro a partir de uma amostra composta por empresas listadas na Bolsa de Valores de São Paulo (BMF\&Bovespa), testando a capacidade de precificação setorial dos fatores de risco presentes no recente modelo de 5-fatores, proposto por Fama e French (2015a). Para a realização da pesquisa foram utilizadas as empresas listadas na Bovespa entre o período de janeiro de 2008 e dezembro de 2015. Os resultados apontam para uma importância maior do prêmio de risco atrelado aos investimentos, estatisticamente significativo em três dos cinco setores da economia estudados. 
Palavras-chave: Modelo de Precificação. 5-Fatores de Risco. Mercado de Ações Brasileiro. Carteiras Setoriais. Regressões SUR.

\begin{abstract}
The assets risk premium is the central variable of the finance models that seek to estimate the cost of capital of the companies, cost this employee, for example, in the evaluation of the stock price. There are several models used to calculate the risk premium, with Fama and French models being widely known and widely disseminated. In 2015, Fama and French introduced a new model with the introduction of two new risk premiums. Due to the relevance of the theme and the possibility of obtaining new information from this new model, the objective of this paper is to conduct a study in the Brazilian stock market from a sample composed of companies listed on the São Paulo Stock Exchange (BMF\&Bovespa), testing the ability of sectoral pricing in the risk factors present in the recent 5- Factors, proposed by Fama and French (2015a). In order to carry out the research, the companies listed on the Bovespa were used between January 2008 and December 2015. The results point to a greater importance of the investment risk premium, being statistically significant in three of the five sectors of the economy studied.
\end{abstract}

Keywords: Pricing Model. 5-Risk Factors. Brazilian Stock Market. Sector Portfolios. Regressions SUR.

\title{
1 INTRODUÇÃO
}

"Wall Street: o dinheiro nunca dorme". O jargão não é apenas nome de filme, mas sim reflexo das constantes oscilações pelas quais passam diariamente os preços do mercado de ações. Com intuito de entender os fatores que dão origem aos retornos, investidores e acadêmicos buscam alcançar há décadas os elementos-chave que movimentam o mercado acionário.

As análises técnica e fundamentalista são as ferramentas utilizadas no dia a dia por traders, assets management, fundos institucionais, agentes que estão na linha de frente das negociações, na tentativa de interpretar as oscilações e bater o mercado.

Por outro lado, os acadêmicos se esforçam para entender os fatores que explicam o retorno das ações. Busca-se, dessa forma, a formulação de um modelo de precificação, capaz de refletir os fatores-chave que explicam o retorno do mercado com a maior precisão possível.

$\mathrm{Na}$ literatura, após o CAPM, o modelo mais difundido foi o multifatorial de Fama e French (1993) que elege os fatores de risco como elementos do modelo de precificação. Os fatores de risco podem ser definidos como exposições ao risco refletidas nos retornos de determinada classe de ativos.

Nesse contexto, modelos de fatores de risco têm sido utilizados não somente no campo acadêmico, mas também por fundos quantitativos que tentam captar excessos de retornos a partir de fatores de risco presentes no ambiente de negócios e macroeconômico. A estratégia de investimento baseada em fatores de risco busca identificar direcionadores/vetores (drivers) de retornos. No campo macroeconômico pode-se citar como fatores relevantes: crescimento econômico, taxa real de juros, inflação, taxa de inadimplência, risco país. Já no ambiente de negócios, liquidez, valor de mercado, alavancagem, além de diversos índices obtidos a partir de dados contábeis.

O modelo de quatro fatores desenvolvido por Carhart (1997) sucedeu o modelo de 3fatores de Fama e French e tem origem na estratégia de momento de Jegadeesh e Titman (1993). Tal estratégia surge a partir da constatação da existência de retornos anormais positivos para uma estratégia baseada na seleção de papéis tendo como parâmetro a performance passada. A estratégia estabelece uma posição vendida para papéis com baixo desempenho recente e comprada naqueles que vêm de um recente rally de alta ou acúmulo de ganhos nos últimos 12 meses. 
Seguindo essa linha de estudos, Fama e French (2006) derivam a partir do modelo de dividendo descontado a influência do book to market (B/M - relação entre o valor patrimonial e o valor de mercado) na captação dos retornos. A principal premissa do modelo de 5-fatores proposto por Fama e French (2015a) é que o valor presente de determinada ação é calculado a partir dos dividendos esperados em exercícios financeiros futuros, testando a robustez desse modelo em trabalhos posteriores (Fama \& French, 2014, 2015b).

O objetivo do trabalho é realizar um estudo no mercado de ações brasileiro a partir de uma amostra composta por empresas listadas na Bolsa de Valores de São Paulo (BMF\&Bovespa), testando a capacidade de precificação setorial dos fatores de risco presentes no recente modelo de 5-fatores, proposto por Fama e French (2015a).

É importante enfatizar que a ideia do presente estudo não é replicar o modelo original de 5-fatores de Fama e French (2015a), mas sim utilizar os cinco fatores de risco propostos pelos autores na composição de um modelo de apreçamento, por meio de uma metodologia adaptada as condições do mercado de capitais brasileiro.

A partir da seleção da amostra e cálculo dos fatores de risco obtiveram-se os modelos de precificação a serem aplicados para carteiras setoriais montadas ano a ano. A ideia é mostrar a capacidade do modelo de precificar os retornos semanais médios dos principais setores de atuação das empresas listadas na Bovespa (materiais básicos, consumo cíclico, consumo não cíclico, industrial e utilidade pública).

\section{REVISÃO DA LITERATURA}

A teoria de seleção de carteiras de Markowitz (1952) foi o passo inicial para o desenvolvimento de diversos modelos de precificação de ativos, que buscam determinar o retorno esperado. A hipótese central é a de que investidores tomam suas decisões lastreadas em dois parâmetros presentes nas distribuições de probabilidade dos ativos: a média e a variância. Essas métricas remetem à clássica relação risco-retorno, sempre inerente ao processo de escolha de um investimento. Por essa razão o arcabouço de Markowitz também é conhecido na literatura como modelo de média-variância.

Levando em conta as premissas dessa teoria, para compor uma carteira de investimento ótima o agente econômico deveria alocar seus recursos no portfólio que apresentasse menor variância dentre um conjunto infinito de carteiras que trazem determinado retorno esperado (Caldeira, Moura, \& Santos, 2013).

Nesse contexto, o retorno de uma carteira de investimentos pode ser mensurado por meio dos retornos esperados individuais dos ativos que a compõem, ponderados pelos seus respectivos pesos na carteira (Investment Science p.166). Já a variância da carteira pode ser obtida a partir das variâncias individuais dos ativos.

A diversificação é um princípio básico dessa teoria. É considerada capaz de mitigar o risco não sistemático (das próprias empresas), sempre que os ativos não possuam correlação perfeita entre si (diferente de $\rho=1$ ).

O risco sistemático (do mercado), por sua vez, não pode ser eliminado, mas pode ser otimizado por meio da carteira de mínima variância, que gera para o investidor o menor patamar de risco.

Nos modelos de avaliação de ação, o prêmio de risco dos ativos é a variável central na explicação do retorno desses ativos. Nesse contexto, duas linhas de pesquisa se destacam no aprimoramento do estudo do modelo CAPM. Uma dessas linhas de pesquisa focou no tratamento dinâmico do modelo, em que os fatores de risco variam ao longo do tempo. Esses modelos são chamados de CAPM condicional. Nesses modelos não se pressupõe que a relação entre o retorno do ativo e o fator de risco seja estática. Busca-se refletir as mudanças que ocorrem no mercado ao longo do tempo.

A outra linha de pesquisa buscou estudar múltiplos fatores de risco capazes de explicar o retorno do ativo alvo. O foco recaiu sobre quais os fatores da organização seriam capazes de explicar o desempenho da empresa. É nessa linha que a presente pesquisa se encaixa e busca aplicar o modelo mais recente de Fama e French, o modelo de 5-fatores. Nas seções 2.1 
a 2.3 será explorada a evolução do modelo uni fator (modelo CAPM) até o modelo de múltiplos fatores (5-fatores) mais atual.

\subsection{Capital Asset Pricing Model}

A teoria de carteiras foi a base para os trabalhos de Sharpe (1964), Lintner (1965) e Mossin (1966) que formulam o modelo CAPM (Capital Asset Pricing Model). A versão SharpeLintner é a mais difundida na literatura, estabelecendo que o retorno esperado do ativo $E\left(R_{i}\right)$ equivale à soma da taxa livre de risco, $R_{f}$, com o prêmio de risco do ativo, $\beta_{i m}\left[E\left(R_{m}\right)-R_{f}\right]$. $E\left(R_{m}\right)$ é o retorno esperado da carteira de mercado (risco sistemático).

O parâmetro $\beta_{\text {im }}$ do CAPM é o cerne do modelo e busca captar a sensibilidade do ativo a oscilações da carteira de mercado. É calculado por meio do quociente entre a covariância ativo-mercado e a variância do retorno do mercado.

Portanto, na medida em que o risco sistemático não pode ser mitigado, investidores teoricamente seriam compensados por maiores retornos ao carregarem carteiras com maior risco embutido, por sua vez, captado pela sensibilidade do beta de mercado.

Outra conhecida versão é a de Black, conhecida como Zero Beta CAPM. A diferença em relação à vertente anterior é a substituição da taxa livre de risco pelo retorno de uma carteira Z, sem nenhuma correlação com a carteira de mercado.

$O$ resultado do modelo Zero Beta é interessante. Fortalece o CAPM na medida em que mostra que a carteira de mercado eficiente, em termos de média-variância, pode ser alcançada não só a partir de empréstimos à taxa livre de risco (premissa do CAPM Sharpe-Lintner), como também pela venda a descoberto de ativos que carregam risco (Fama \& French, 2004).

O CAPM, nas suas variadas versões, é construído sobre a chamada hipótese de mercado eficiente, abarcando como premissas: a eliminação do risco diversificável (via construção de um portfólio com mínima variância), inexistência de custos de transação, informações simétricas, investidores racionais e avessos ao risco, equilíbrio dos mercados, entre outras.

Apesar da incapacidade das premissas de refletir as condições naturais do mercado, o CAPM serviu (e ainda serve) como um modelo teórico analítico-base, para a construção de modelos mais complexos.

O CAPM postula que o retorno de uma ação pode ser explicado unicamente pelo parâmetro beta. No entanto, a partir da década de 80 , surgem na literatura evidências empíricas contrárias à capacidade explicativa do beta de mercado, como os trabalhos de Stambaugh (1982) e Fama e French (1992). Tais estudos mostram que a relação beta-retorno é menos acentuada (ou mais horizontalizada) do que prevê o modelo Sharpe-Lintner.

Relevante ressaltar a crítica de Roll (1977) acerca da impossibilidade de teste do modelo CAPM na medida em que a verdadeira carteira de mercado, com a totalidade dos ativos negociáveis presentes na economia, não é passível de replicação.

\subsection{O modelo de 3-fatores de Fama e French}

$\mathrm{Na}$ busca por um modelo de precificação com maior alcance e capacidade para explicar o retorno de papéis listados na NYSE, AMEX e NASDAQ, Fama e French (1992) elaboram um modelo com 3-fatores: risco de mercado, tamanho e índice B/M.

A amostra é composta por ações das três Bolsas de Valores entre 1963 e 1991. Para calcular os fatores do modelo, Fama e French (1992) construíram portfólios para replicar o fator tamanho (Small minus Big - SMB), definido pela capitalização de mercado das empresas, e o fator book to market (High minus Low - HML). O excesso de retorno do mercado, $R_{m, t}-R_{l r, t}$, presente no modelo de único fator, também comporá o modelo:

$$
R_{i, t}-R_{l r, t}=a_{i}+b_{i}\left(R_{m, t}-R_{l r, t}\right)+s_{i}\left(S M B_{t}\right)+h_{i}\left(H M L_{t}\right)+e_{i t}
$$


Em que $R_{i, t}$ é o retorno da carteira i no mês $\mathrm{t} ; R_{l r, t}$ retorno do ativo com taxa livre de risco no mês $\mathrm{t} ; R_{m, t}$ o retorno da carteira de mercado no mês t; $S M B_{t}$ o prêmio pelo fator tamanho no mês $\mathrm{t}$; $H M L$ o prêmio pelo fator B/M no mês $\mathrm{t}$; $e_{i t}$ o termo de erro do modelo.

Os autores encontram evidência de prêmios positivos para os três fatores de risco; a regressão das carteiras do modelo apresenta intercepto estatisticamente igual a zero, o que valida os fatores de risco como proxies para o modelo de precificação. O modelo conseguiu neutralizar problemas de multicolinearidade entre os fatores, além de mostrar capacidade explicativa superior ao CAPM para os retornos de ações no mercado financeiro americano.

Outro resultado interessante, o B/M possui maior poder explicativo para os retornos médios que o efeito tamanho. Dividindo a amostra em 12 carteiras, tendo como base o B/M, empresas com menor B/M obtiveram retorno médio de $0,3 \%$ enquanto as com o maior índice alcançaram $1,83 \%$ de retorno no período analisado. A explicação desse fenômeno se pauta no fato de ações com elevado B/M serem consideradas mais arriscadas que aquelas com B/M reduzido. O maior retorno obtido seria então, segundo Fama e French (1992), uma maneira de compensar o maior risco carregado pelos papéis com alto $\mathrm{B} / \mathrm{M}$.

\subsection{O modelo de 5-fatores de Fama e French}

Fama e French (2006) derivam a partir do modelo de dividendo descontado a influência do B/M na captação dos retornos. A principal premissa desse modelo é que o valor presente de determinada ação é calculado a partir dos dividendos esperados em exercícios financeiros futuros.

$M_{t}$ é o somatorio dos dividendos descontados por i, a taxa interna de retorno (TIR) dos dividendos esperados, fornecendo o preço da ação no periodo t. Por meio de uma derivação contábil, chegam ao valor da ação como: o retorno por ação, $R P A$, menos a variação do valor contábil do patrimonio líquido por ação, $\Delta B_{t}$.

$$
\begin{aligned}
& M_{t}=\sum \frac{E\left(R P A_{t+1}-\Delta B_{t+1}\right)}{(1+i)^{t}} \\
& \Delta B_{t}=B_{t}-B_{t-1}
\end{aligned}
$$

Dividindo o valor presente dos dividendos (que em tese deve corresponder ao preço de mercado da ação, $M_{t}$ ) pelo valor da conta patrimonio líquido tem-se o inverso da métrica $\mathrm{B} / \mathrm{M}$ :

$$
\frac{M_{t}}{B_{t}}=\frac{\sum \frac{E\left(R P A_{t+1}-\Delta B_{t+1}\right)}{(1+i)^{t}}}{B_{t}}
$$

A derivação a partir desse fluxo de caixa permite as seguintes inferências: ceteris paribus um valor menor de $M_{t}$ (B/M mais elevado) implica maior retorno esperado; mantendo fixos $B_{t}, M_{t}$ e o lucro esperado, o aumento no crescimento do balanço patrimonial (investimento, expansão de ativos) gera menores retornos esperados.

A importância desse modelo de avaliação é a de fornecer fatores que, incluídos no modelo de precificação, possam captar com eficiência os retornos esperados. Nesse contexto, motivados pelos trabalhos de Novy-Marx (2012) e Aharoni, Grudy e Zeng (2013), que encontram evidências favoráveis para a relação retornos médios e lucratividade, e para a relação retornos médios e investimento, respectivamente, Fama e French (2015a) adicionam dois novos parâmetros ao modelo original de três fatores:

$$
R_{i, t}-R_{l r, t}=a_{i}+b_{i}\left(R_{M t}-R_{F t}\right)+s_{i} S M B_{t}+h_{i} H M L_{t}+r_{i} R M W_{t}+c_{i} C M A_{t}+e_{i t}
$$


O fator $R M W$ é calculado a partir da lucratividade operacional aferida pela companhia. O índice financeiro que possibilita esse cálculo é a relação lucro operacional/PL. Logo, o fator mede a diferença de retorno obtida por ações com desempenho operacional robusto e fraco.

Já o fator de risco CMA é calculado tendo como parâmetro a variação dos ativos totais de um ano para o outro. A ideia do fator é medir a diferença de retorno entre empresas que expandiram com mais intensidade seus ativos totais (arrojadas) e empresas que tiveram expansão mais moderada do ativo ou que, até mesmo, tiveram uma contração na sua posição de ativos (conservadoras).

Em trabalho posterior Fama e French (2015b) testam a robustez desse modelo de 5fatores a partir de anomalias, sugeridas pela literatura - beta de mercado, recompras de ações, volatilidade, accruals e momento. Os resultados mostram que retornos de firmas lucrativas e investimento conservador ( $R M W$ e CMA positivos) captam altos retornos médios associados a baixo beta de mercado, recompra de ações e baixa volatilidade.

Testando o modelo de 5-fatores em mercados de capitais internacionais, Fama e French (2015c) confirmam a existência de uma relação positiva do B/M e da lucratividade, e negativa do investimento, com os retornos médios dos mercados de ações da América do Norte, Europa e Pacífico da Ásia. O modelo também é testado para o mercado japonês fornecendo evidência favorável para o poder explicativo do $\mathrm{B} / \mathrm{M}$, o que não ocorre com os fatores lucratividade e investimento.

\section{METODOLOGIA}

A presente pesquisa procura investigar se o modelo adaptado de 5-fatores é capaz de precificar com acurácia as variações dos retornos de carteiras setoriais.

O método adotado para construção das carteiras (usadas no cálculo dos fatores de risco) é o modelo $2 \times 2 \times 2 \times 2$. Esse método produz 8 carteiras, segmentadas pela mediana das métricas dos quatro fatores de risco ( $S M B, H L M, R M W, C M A)$.

Algumas diferenças em relação ao método de Fama e French (2015a) devem ser destacadas. Primeiramente os autores constroem suas carteiras a partir de retornos mensais value wheighted. Neste trabalho são usados retornos semanais equally wheighted. As métricas dos fatores de risco sofrem uma adaptação, relacionada ao fator $R M W$, explicada na seção 3.1.

Quanto aos critérios de inclusão na amostra seguiu-se os adotados por Leite, Pinto e Klotzle (2016), que buscam adaptar a amostra às condições do mercado acionário brasileiro. As justificativas teóricas da metodologia adotada são detalhadas na seção 3.2.

\subsection{Amostra e Coleta de Dados}

A amostra foi montada a partir de ações listadas na BMF\&Bovespa entre janeiro de 2008 e dezembro de 2015. A escolha do período é justificada pela grande quantidade de ofertas públicas iniciais (IPO's) que ocorrem entre 2006 e 2008. Nesse sentido, a coleta de dados a partir de 2008 fornece a possibilidade de trabalhar com uma amostra mais ampla e robusta para o modelo de precificação. Entre fevereiro de 2006 e junho de 2008 o mercado doméstico de ações passou por um boom em termos de abertura de capital. Nesse período 94 IPO's foram autorizadas pela Comissão de Valores Mobiliários, reflexo do favorável cenário macroeconômico pelo qual passava a economia brasileira.

No estudo foram utilizadas séries de retorno semanais, obtidas a partir dos preços de fechamento das empresas incluídas na amostra. Todos os dados foram coletados do terminal Bloomberg, exceto as taxas SWAP-DI de 30 dias, obtidas no sistema de recuperação de informações da BMF\&Bovespa.

A seleção inicial dos ativos a comporem as carteiras é realizada ano a ano, de forma prospectiva, ao final de dezembro de cada ano. Em outras palavras, a posição de empresas listadas com negociação ativa ao final de dezembro de cada ano é utilizada na amostragem bruta inicial, que passará pelos critérios de exclusão subcitados. A amostra líquida, obtida após aplicação dos critérios excludentes, fornecerá os papéis que comporão as carteiras do ano subsequente. 
Nesse contexto, a amostra é redefinida a partir de uma periodicidade anual, com base nos seguintes critérios:

- A ação deve ser negociada em pelo menos $50 \%$ dos pregões do ano, critério de liquidez;

- Excluídas ações com Patrimônio Líquido (PL) negativo, empresas com $P L<0$ caracterizam estado de insolvência, podendo enviesar os fatores $H M L$ e $R M W$, que utilizam diretamente o valor contábil do PL no seu cálculo;

- Excluídos bancos e seguradoras, a composição do balanço patrimonial e do demonstrativo de resultados das empresas desses segmentos possuem características particulares, demandando metodologia de avaliação própria para os setores. Sua inclusão pode enviesar o modelo.

Aplicando os critérios supracitados foram obtidas as seguintes quantidades de ativos, ano a ano: 88 em 2008, 111 em 2009, 197 em 2010, 194 em 2011, 193 em 2012, 175 em 2013, 188 em 2014, 178 em 2015. Obtendo os ativos filtrados, os mesmos foram segmentados em carteiras, cujo critério de seleção foi o setorial. A partir das carteiras montadas realizou-se o cálculo dos fatores de risco.

A série de retornos semanais de 2008 a 2015 forneceu o total de 417 observações (semanas) que, por meio dos cálculos de fatores de risco semanais, produziu 417 dados para a estimação do modelo de precificação

\subsection{Variáveis base}

Utiliza-se o retorno semanal das ações ajustado para inclusão de dividendos. O terminal Bloomberg possui um recurso de configuração que permite embutir no retorno dos papéis os dividendos obrigatórios, dividendos adicionais e juros sobre capital próprio, além de ajustar os preços históricos de ações para splits, inplits, aumentos e reduções de capital. Os ajustes para distribuição de dividendos e eventos societários realizados pelo terminal evita distorções nos retornos semanais, além de embutir o retorno global aferido pelo acionista.

Aplica-se ao retorno nominal com dividendos o logaritmo neperiano para transformação dos retornos discretos em contínuos.

$$
R_{i, t}=\ln \left(\frac{D i v_{i, t}+P_{i, t}}{P_{i, t-7}}-1\right)
$$

Em que $P_{i, t}$ é o preço de fechamento do pregão do dia t e $P_{i, t-7}$ o preço de fechamento do dia equivalente da semana anterior, t-7. O quociente das duas variáveis fornece a variação semanal do preço das ações.

Adota-se a hipótese de pesos ponderados uniformes (equally wheighted) para o cálculo do retorno médio semanal da carteira de mercado, aferido a partir das ações que atenderam aos critérios de elegibilidade.

$$
R_{c, t}=\frac{1}{N}\left(\sum_{i=1}^{n} R_{i, t}\right)
$$

Em que $R_{c, t}$ o retorno semanal da carteira c na semana t, $R_{i, t}$ o retorno da ação $i$ na semana $t$ e $N$ o número de ações presentes na carteira. A escolha pela adoção de retornos igualmente ponderados evita um problema inerente ao mercado de ações brasileiro: a elevada concentração da negociação em um pequeno número de papéis. $A$ baixa pulverização entre ações em relação ao volume negociado é uma característica comum dos mercados de capitais de países emergentes. 
Utiliza-se o índice B/M, calculado a partir do patrimônio líquido, extraído do balanço patrimonial em 31 de dezembro de $\mathrm{t}-1$, e do valor de mercado concatenado na mesma data, 31 de dezembro de $\mathrm{t}-1$.

$$
\frac{B}{M_{i, t}}=\frac{V C_{P L, \text { dezembro }(t-1)}}{V M_{\text {dezembro }(t-1)}}
$$

O valor de mercado de uma ação $(V M)$ é o reflexo da expectativa do mercado na capacidade de gerar fluxo de caixa e aferir lucros de uma companhia. Já o patrimônio líquido ( $V C_{P L}$, é a diferença entre o valor contábil dos ativos e passivos, é o valor residual entre o débito (ativos) e crédito (passivos) do balanço patrimonial de uma empresa.

Diferente da estratégia de momento de Jegadeesh e Titman (1993), que utiliza a performance das ações no mercado de capitais para cálculo do fator de risco WML(Winning Minus Losers), o fator RMW (Robust Minus Weakers) busca refletir a performance operacional de uma companhia, ou seja, sua capacidade de gerar de fluxo de caixa para o acionista.

No trabalho de Fama e French (2015a) a métrica utilizada é o lucro operacional dividido pelo patrimônio líquido. O lucro operacional é obtido a partir da receita líquida deduzida das despesas de vendas, gerais e administrativas. Pela dificuldade de acesso aos dados brasileiros dessas contas específicas do demonstrativo de resultado, realizou-se uma adaptação. O lucro operacional foi substituído pelo EBIT. O fator é calculado a partir do índice financeiro EBIT/PL.

$$
R M W=\frac{E B I T_{d e z(t-1)}}{V C_{P L, d e z(t-1)}}
$$

Esse índice é similar ao ROIC (return on invested capital), métrica que propicia avaliar a capacidade operacional de uma empresa de remunerar o capital investido pelo acionista. $O$ $R O I C$ é calculado pelo índice EBIAT/Capital Investido. A medida do denominador é o lucro antes de juros depois de impostos (Earnings Before Interest After Taxes - EBIAT) e o divisor o capital investido (ou o capital social integralizado), conta integrante do Patrimônio Líquido.

Essa medida reflete a produtividade básica do capital aplicado no negócio (é o retorno obtido por cada unidade monetária aplicada no negócio). Quanto maior o $R O I C$, mais atrativo é investir na companhia.

Nesse ponto é interessante destacar que dois dos fatores de risco utilizam o PL na sua composição (HML e RMW). O uso desse componente do balanço patrimonial como ferramenta de avaliação possui prós e contras.

Partindo da premissa de que as informações contábeis carregam as características qualitativas fundamentais - relevância e representação fidedigna - pode-se considerar que o PL é uma medida estável, capaz de refletir a geração de valor por parte da organização. Por outro lado, pode ser influenciado por decisões contábeis, no que tange à mensuração dos ativos e passivos. Como exemplos podem ser citados os procedimentos adotados na redução ao valor recuperável do ativo imobilizado (testes de impairment), o método adotado no controle e avaliação de estoques, dentre outras decisões capazes de afetar o resultado contábil e, consequentemente, a posição do PL (Damodaran, 2012).

Tendo como base uma medida de lucratividade, o fator $R M W$ é determinado pelos mesmos fundamentos do modelo de fluxo de caixa descontado: o crescimento esperado, o risco do negócio (determinante da taxa de desconto) e o fluxo de caixa gerado (resultado aferido). Nesse sentido, firmas com maior crescimento esperado, reduzido risco específico e maior distribuição de dividendos, ceteris paribus, possuem maior EBIT/PL.

O quarto fator - CMA (Conservative minus Agressive), também chamado de INV (taxa de investimento) - por sua vez, é calculado em função da variação dos ativos das empresas. O cálculo desse fator de risco é feito pela diferença na posição dos ativos totais entre o final do exercício $t$-1 e o final do exercício $t$-2. A ideia do fator é medir a taxa ou variação de investimento das companhias, refletida na expansão de ativos no balanço patrimonial. 


$$
C M A=\frac{A_{\operatorname{dez}(t-1)}-A_{\operatorname{dez}(t-2)}}{A_{\operatorname{dez}(t-2)}}
$$

São duas as formas de uma empresa realizar a supracitada expansão: a despesa de capital líquida (CAPEX - capital expenditure) - montante da despesa de capital que supera a depreciação - e a necessidade de capital de giro.

Os fatores de risco mencionados nesta seção podem ser interpretados como carteiras diversificadas, capazes de prover diferentes combinações de exposição às métricas: capitalização de mercado $(S M B)$, índice $\mathrm{B} / \mathrm{M}(H M L)$, índice EBIT/PL $(R M W)$ e variação de ativos $(C M A)$.

\subsection{As carteiras setoriais}

As carteiras setoriais utilizadas neste estudo são formadas a partir das empresas que atenderam aos critérios de inclusão para cálculo dos fatores de risco. Os setores elencados foram: materiais básicos, consumo cíclico, consumo não cíclico, industrial e utilidade pública, definidos a partir do filtro de setores do terminal Bloomberg, seguindo estrutura semelhante à dos índices setoriais elaborados pela BM\&FBovespa:

- Carteira Materiais Básicos - abrange segmentos como a indústria química, papel e celulose, metalurgia, mineração e siderurgia. Pode ser considerado o pilar da cadeia produtiva, na medida em que fornece as matérias-primas e insumos para os diversos campos da atividade produtiva;

- Carteira Consumo Cíclico - composta pelos segmentos atacadista, varejista, vestuário, têxtil, autopeças e equipamentos, viagens e lazer, hotéis e restaurantes, construtoras de imóveis. Este é um setor muito acompanhado por analistas e economistas que trabalham com conjuntura econômica, considerado um dos principais termômetros do nível de atividade econômica;

- Carteira Consumo Não Cíclico - abarca a indústria de alimentos e bebidas, agropecuária, comércio e distribuição, farmacêutica, tabaco, serviços diversos (educacional, laboratorial, rodovias, arrendamento mercantil operacional). Em oposição às características de volatilidade e sazonalidade do setor de consumo cíclico, o não cíclico é caracterizado por uma maior homogeneidade em termos de faturamento;

- Carteira Industrial - composta por empresas que atuam na indústria de bens de capital (máquinas e equipamentos), de logística (serviços e material de transporte) e equipamentos elétricos;

- Carteira Utilidade Pública - congrega os subsetores de abastecimento de água, energia elétrica, gás e saneamento. São serviços prestados por meio de delegação do poder público que buscam atender à satisfação do bem-estar da coletividade.

Tabela 1

\section{Correlação de Spearman entre as Carteiras Setoriais}

\begin{tabular}{cccccc}
\hline & Mat Básicos & Cons Cíclico & $\begin{array}{c}\text { Cons Não } \\
\text { Cíclico }\end{array}$ & Industrial & Util Pública \\
\hline Mat Básicos & 1 & & & & \\
Cons Cíclico & 0,6084 & 1 & & & \\
Cons Não Cíclico & 0,4255 & 0,4468 & 1 & 1 & \\
Industrial & 0,7836 & 0,7260 & 0,7260 & 1 \\
Util Pública & 0,4252 & 0,4464 & 0,9999 & 0,6633 & 1 \\
\hline
\end{tabular}

Nota. Fonte: Elaborado pelos autores.

A Tabela 1 demonstra a correlação existente entre os retornos semanais das carteiras setoriais. As correlações mais altas ocorrem entre os setores industrial e materiais básicos $(\rho=0,7836)$ e entre o setor utilidade pública e consumo não cíclico $(\rho=0,9999)$. Todos os setores apresentam média ou alta correlação.

A presença de menores correlações por parte do setor de utilidade pública com os retornos dos outros segmentos (última linha da tabela) se justifica por pertencer a uma 
estrutura de mercado particular, conforme será explicado na seção 4.2. Sua maior correlação com o setor de consumo não cíclico $(\rho=0,9999)$ manifesta uma característica comum entre os setores: a menor dependência do nível de atividade econômica na medida em que ambos provêm serviços essenciais para a sociedade, caracterizados por reduzida elasticidade da demanda.

A partir das carteiras setoriais montadas com base em retornos equally weighted são calculados os prêmios dos setores. A junção desses parâmetros origina o seguinte modelo de regressão:

$$
R_{\text {CarteiraSetorial }, t}-R_{l r, t}=a_{i}+b_{i}\left(R_{M t}-R_{F t}\right)+s_{i} S M B_{t}+h_{i} H M L_{t}+r_{i} R M W_{t}+c_{i} C M A_{t}+e_{i t}
$$

A seção 4 detalha os resultados obtidos a partir dessas regressões, estimadas pelos métodos OLS (Ordinary Least Squares) e SUR (Seemingly Unrelated Regression).

\subsection{Construção das carteiras para cálculo dos fatores de risco}

O mês base da ordenação é o final de dezembro de cada ano $t$, coincidindo com o final do ano fiscal brasileiro. Na primeira etapa, as ações são ordenadas conforme seu valor de mercado ao final de dezembro do ano $t$. Essa ordenação, feita em sequência decrescente, permite a segmentação das empresas listadas em dois portfolios: B (Big) e S (Small).

A segunda ordenação utiliza o índice B/M como parâmetro, propiciando a formação de duas novas carteiras $\mathrm{H}$ (High) e $\mathrm{L}$ (Low). Na terceira ordenação as ações são classificadas conforme o índice EBIT/PL, segmentando as carteiras em R (Robust) e W (Weak). Finalmente, na quarta ordenação, a métrica passa a ser a variação total de ativos, ou a taxa de investimento, levando ao desdobramento das carteiras em C (Conservative) e A (Agressive). Esse procedimento é repetido oito vezes, ao final de cada ano do período estudado (2008 a 2015).

Em todas as quatro ordenações o parâmetro utilizado para separar as carteiras é a mediana das variáveis-base (valor de mercado, B/M, EBIT/PL, variação do ativo total). A mediana serve, portanto, como linha divisória de segmentação das carteiras. Essa forma de construir as carteiras produziu oito conjuntos de ativos diversificados (carteiras) que permitiram, a cada ano, o cálculo dos fatores de risco, descrito na seção a seguir.

\subsection{Cálculo dos Fatores de Risco}

Os principais trabalhos de precificação com fatores de risco, como é o caso de Fama e French (1993), usam retornos mensais para calculá-los. Em compensação, analisam um extenso período de tempo. No caso deste estudo de 1963 a 1991.

No presente trabalho, dada a menor extensão do período investigado, opta-se por trabalhar com retornos semanais, com o intuito de aumentar a quantidade de observações e, desse modo, aferir maior precisão no cálculo dos fatores de risco.

O fator mercado é calculado a partir da diferença entre os retornos semanais uniformes (equally wheighted) e a taxa livre de risco semanal, $R_{l r}$, computada a partir de interpolação linear realizada a partir da taxa SWAP-DI de 30 dias. A diferença entre as duas métricas fornece o excesso de retorno $R_{c, t}$ da carteira c no dia t:

$$
R_{c, t}=\frac{1}{N}\left(\sum_{i=1}^{n} R_{i, t}\right)-R_{l r}
$$

Calculado semanalmente, a partir de uma posição comprada na carteira com ações de empresas com baixa capitalização de mercado (Small) e vendida em ações de empresas de grande valor de mercado (Big). A diferença do retorno semanal entre as carteiras fornece o fator de risco SMB. 
Calculado semanalmente, a partir de uma posição comprada na carteira com ações de empresas com elevada razão B/M (Hig) e vendida em ações de empresas com reduzida razão (Low). A diferença de retorno entre as duas posições fornece o fator de risco HML.

Calculado semanalmente, a partir de uma posição comprada na carteira com ações de empresas que obtiveram desempenho operacional robusto (Robust) e vendida em ações de empresas com fraca performance operacional (Weak). Essas medidas de desempenho foram computadas com base na relação lucro operacional/PL obtida ao final de cada ano $\mathrm{t}-1$. A diferença de retorno entre as duas posições fornece o fator de risco $R M W$.

Calculado semanalmente, a partir de uma posição comprada na carteira com ações de empresas que apresentaram reduzidas taxas de investimento entre os exercícios financeiros (Conservative) e vendida em ações de empresas que expandiram seus ativos com maior intensidade (Agressive). A diferença de retorno entre as duas posições fornece o fator de risco CMA.

A Tabela 2 ilustra a presença de uma baixa correlação entre os fatores de risco, atributo positivo para o modelo de precificação, na medida em que reduz possíveis problemas de muticolinearidade entre as variáveis do modelo.

Tabela 2

Correlação de Spearman entre as carteiras setoriais

\begin{tabular}{cccccc}
\hline & Rm-Rf & SMB & HML & RMW & CMA \\
\hline Rm-Rf & 1 & & & & \\
SMB & $-0,2449$ & 1 & & & \\
HML & 0,2097 & $-0,0426$ & 1 & & \\
RMW & $-0,2423$ & $-0,0402$ & $-0,0303$ & 1 & 1 \\
CMA & $-0,0884$ & 0,0447 & 0,0029 & 0,0473 & \\
\hline
\end{tabular}

Nota. Fonte: Elaborado pelos autores.

Destaques para correlação inversa entre o prêmio de mercado e o fator SMB $(\rho=-$ $0,2449)$ e o fator RMW ( $\rho=-0,2423)$, as mais intensas da matriz de correlação.

\section{RESULTADOS}

Esta seção apresenta os resultados da pesquisa. Os métodos são aplicados para os retornos das cinco carteiras setoriais propostas, cada um deles em função dos cinco fatores de risco calculados. A partir dos prêmios das carteiras setoriais usados como variável explicada e dos fatores de risco, como variáveis explicativas, são formadas cinco regressões lineares múltiplas, que buscam explicar a relação entre os retornos das carteiras setoriais e os fatores de risco.

A metodologia SUR é processada em duas etapas. No primeiro passo os resíduos das regressões $O L S$ são utilizados para estimar a matriz de covariância dos erros das equações. Num segundo momento os coeficientes das regressões foram estimados via GLS, quando são aplicadas as covariâncias anteriormente estimadas (Duarte, Lamounier, \& Takamatsu, 2007).

Se a matriz de covariância dos erros, obtida na primeira etapa, for nula, os métodos OLS e SUR são equivalentes. Tratando-se de uma matriz de covariância não nula, o método SUR realiza a correção dos resíduos, gerando maior acurácia no processo de estimação (Neves, 1996).

Os resultados obtidos pelo estudo corroboram a presença de uma matriz de covariância não nula para o modelo de precificação, refletida na superioridade do $R^{2}$ ajustado das regressões estimadas pelo método $S U R$ em comparação às estimadas por OLS, como demonstrado na seção 4.2 .

A opção pelo método SUR segue a abordagem de Costa e Neves (2000), que, aplicado ao modelo de 5-fatores, possibilita testar a significância estatística dos quatro fatores de risco que expandem o modelo CAPM ao mesmo tempo em que reflete a capacidade do procedimento de realizar ajustes no prêmio de mercado das carteiras setoriais. 


\subsection{Análise Estatística}

Inicialmente foi feita uma análise preliminar dos dados a partir da matriz de correlação e visualização gráfica das séries dos fatores de risco. Buscou-se nesse primeiro momento compreender de maneira preliminar a inter-relação das variáveis. Em um segundo momento, realizou-se a estimação pelos métodos OLS e SUR (seção 4.2).

Tabela 3

Teste de Estacionariedade

\begin{tabular}{ccc}
\hline Retornos & $\begin{array}{c}\text { Augmented } \\
\text { Dickey-Fuller }\end{array}$ & p-valor \\
\hline Rm-Rf & $-5,3744$ & $<0,01$ \\
SMB & $-4,9524$ & $<0,01$ \\
HML & $-6,7011$ & $<0,01$ \\
RMW & $-6,8917$ & $<0,01$ \\
CMA & $-6,0431$ & $<0,01$ \\
\hline
\end{tabular}

Nota. Fonte: Elaborado pelos autores.

O teste ADF (Augmented Dickey-Fuller) é realizado para os cinco fatores de risco do modelo com o intuito de verificar se os retornos são estacionários ou não. A importância do teste se dá pelo fato de séries não estacionárias, por terem uma tendência temporal, poderem apresentar alto poder explicativo mesmo que as variáveis não sejam correlacionadas (Brooks, 2014).

Os resultados dos testes de estacionariedade são expostos na Tabela 3 para os retornos dos fatores de risco e na Tabela 6 para os das carteiras setoriais. Todas as séries de retorno testadas não apresentam raiz unitária. São estacionárias.

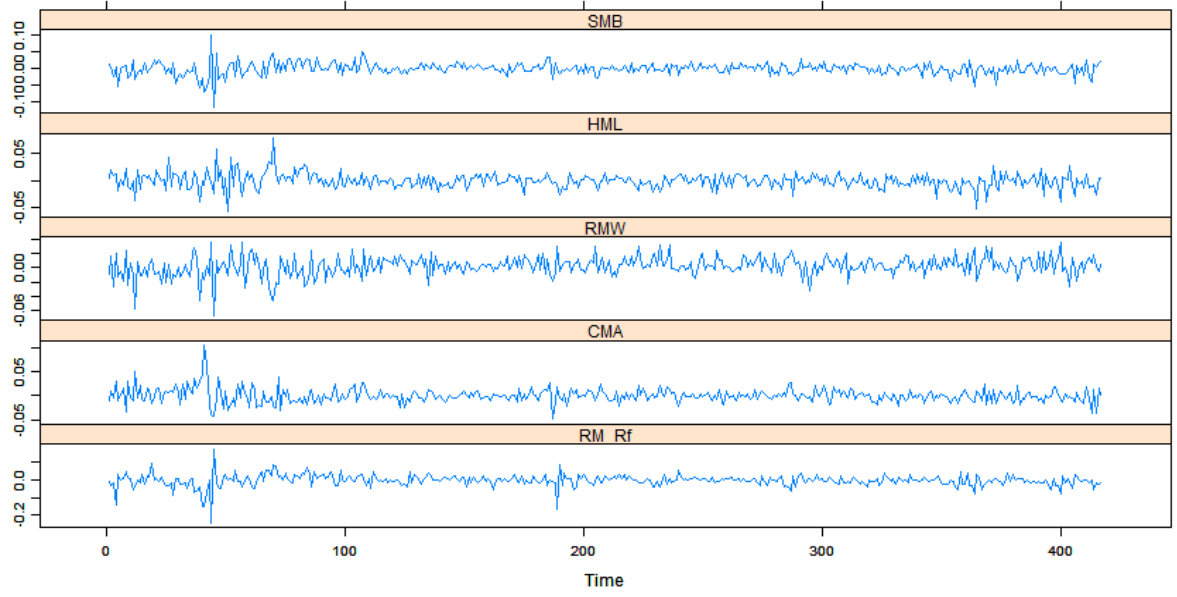

Figura 1. Séries dos retornos semanais dos fatores de risco: jan-2008 a dez-2015

Fonte: Elaborado pelos autores.

Analisando os gráficos dos comportamentos dos fatores de risco, pode-se observar certos comportamentos para o período de análise. O primeiro deles é a forte aceleração da volatilidade dos spreads provocada pela crise subprime, a partir do quarto trimestre de 2008 , mantendo-se até meados de 2009.

Durante esse período, nota-se um comportamento particular por parte do fator CMA, quando os investidores direcionam seus recursos para empresas conservadoras, em detrimento das arrojadas. Esse movimento que reflete um processo de aversão a risco é traduzido no spread positivo do fator CMA.

Outro cenário interessante, uma nova aceleração dos spreads (menos intensa que a ocorrida no final de 2008) ocorre a partir do final de 2010, notadamente no prêmio de mercado (Rm-Rf) e no fator CMA, dessa vez puxada pela crise da dívida europeia, impulsionada por fortes déficits orçamentários atrelados à elevação da dívida pública dos países europeus. $O$ fator, no entanto, que efetivamente desencadeia o novo ciclo de volatilidade foi o início do 
temor dos mercados globais com a possibilidade de default da dívida grega, a partir da segunda metade de 2010. Temor que anos mais tarde, mais precisamente em 30 de junho de 2015, se confirmou com o vencimento do prazo e não pagamento da rolagem da dívida contraída junto ao FMI (Fundo Monetário Internacional).

O terceiro e último alargamento dos spreads da série ocorre a partir do último trimestre de 2014, a partir das eleições presidenciais no Brasil. O aumento da variação é visualizado com clareza nos fatores $H M L$ e $R M W$, persistindo durante o ano de 2015, a partir da permanência da presidente Dilma no poder, atrelado ao cenário macroeconômico de estagflação da economia brasileira.

Tabela 4

\section{Estatística Descritiva dos Fatores de Risco}

\begin{tabular}{lccccc}
\hline Estatística & Rm-Rf & SMB & HML & RMW & CMA \\
\hline Máximo & 0,1700 & 0,1010 & 0,0763 & 0,0357 & 0,1046 \\
Mínimo & $-0,3422$ & $-0,1206$ & $-0,0565$ & $-0,0665$ & $-0,0499$ \\
Média & $-0,0086$ & $-0,0025$ & $-0,0009$ & 0,0019 & 0,00004 \\
Mediana & $-0,0029$ & $-0,0016$ & $-0,0005$ & 0,0028 & $-0,0009$ \\
Desvio-padrão & 0,0489 & 0,0183 & 0,0058 & 0,0135 & 0,0145 \\
Assimetria & $-3,72$ & $-0,49$ & 0,29 & $-0,69$ & 1,15 \\
Curtose & 24,12 & 9,78 & 6,94 & 5,59 & 10,40 \\
Jarque-Bera & $<0,01$ & $<0,01$ & $<0,01$ & $<0,01$ & $<0,01$ \\
Coeficiente de variação & $-5,69$ & $-7,32$ & $-6,44$ & 7,10 & 362,5 \\
\hline
\end{tabular}

Nota. Fonte: Elaborado pelos autores.

Já estatística descritiva dos fatores de risco (Tabela 4) mostra a presença de assimetria à direita para os fatores $\mathrm{Rm}-\mathrm{Rf}, S M B$ e $R M W$, e assimetria à esquerda para o CMA. $\mathrm{O}$ fator $H M L$, por sua vez, apresenta retornos mais simétricos. A assimetria à direita do prêmio de mercado é esperada, dada a combinação de baixo desempenho da bolsa brasileira, atrelada a elevadas taxas de juros; para o fator $R M W$ o contrário era esperado. Em relação ao $C M A$ ocorre o esperado, na medida em que a baixa rentabilidade do mercado de capitais inserida em um contexto macroeconômico pouco favorável para empresas alavancadas gera um desempenho superior por parte das organizações conservadoras.

O fator mercado é o mais volátil $(\sigma=0,0489)$, os demais fatores apresentam menores volatilidades, todas abaixo de $2 \%$. Foi apresentado também o coeficiente de variação (CV), traduzido na razão entre desvio padrão e a média, como forma de mensuração da volatilidade. O teste de Jarque-Bera rejeita a hipótese nula de normalidade para os fatores de risco.

O teste ADF também é realizado para as variáveis explicadas. Os prêmios das carteiras setoriais não apresentam raiz unitária, como mostra a Tabela 5. A análise da existência de raiz unitária é importante para se verificar a possibilidade de modelagem através de uma regressão. A existência de raiz unitária inviabilizaria essa metodologia.

Tabela 5

Teste de Estacionariedade

\begin{tabular}{lll}
\hline Retornos & Augmented Dickey-Fuller & p-valor \\
\hline Mat Básicos & $-6,1297$ & $<0,01$ \\
Cons Cíclico & $-5,2204$ & $<0,01$ \\
Cons Não Cíclico & $-5,7654$ & $<0,01$ \\
Indústrial & $-5,7271$ & $<0,01$ \\
Util Pública & $-6,3722$ & $<0,01$
\end{tabular}

Nota. Fonte: Elaborado pelos autores.

Na figura 2 são apresentadas as séries de retorno dos prêmios setoriais. Interessante notar o comportamento dos prêmios do setor de consumo cíclico durante o segundo choque (2011), são mais intensos que os dos demais setores. Esse fenômeno pode ser explicado pela retirada dos estímulos fiscais anticíclicos concedidos após a crise de 2008 atrelada a uma política monetária contracionista na tentativa de conter a aceleração da taxa de inflação e apreciação do real, após um ano de robusto crescimento econômico (em 2010 o PIB brasileiro cresceu $7,5 \%)$. 


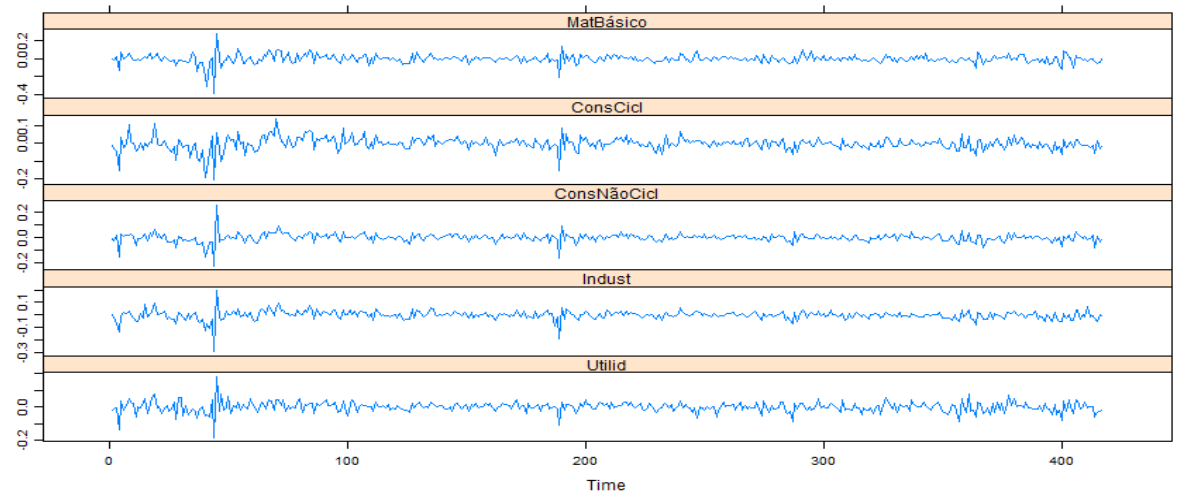

Figura 2. Séries dos retornos semanais das carteiras setoriais: jan-2008 a dez-2015 Fonte: elaborado pelos autores.

A Figura 2 também reflete a volatilidade dos prêmios setoriais trazida pela corrida presidencial. O cenário macroeconômico de desaceleração da China, pressões inflacionárias internas, aumento das taxas de juros, forte depreciação do real conjugado com o início de um processo de ajuste fiscal por parte do governo afetaram o poder de compra do brasileiro e, consequentemente, o nível de consumo. Os setores de consumo cíclico e materiais básicos refletiram com clareza os efeitos desse cenário adverso.

Tabela 6

\section{Estatística Descritiva dos Prêmios das Carteiras Setoriais}

\begin{tabular}{lccccc}
\hline Estatística & $\mathrm{Mb}$ & $\mathrm{Cc}$ & $\mathrm{Cnc}$ & Ind & UtP \\
\hline Máximo & 0,2816 & 0,1381 & 0,2582 & 0,1927 & 0,1791 \\
Mínimo & $-0,3903$ & $-0,2061$ & $-0,2235$ & $-0,2971$ & $-0,1832$ \\
Média & $-0,0034$ & $-0,0023$ & $-0,0016$ & $-0,0032$ & $-0,0009$ \\
Mediana & $-0,0027$ & $-0,0007$ & $-0,0002$ & $-0,0007$ & 0,0005 \\
Desvio-padrão & 0,0487 & 0,0358 & 0,0329 & 0,0348 & 0,0304 \\
Assimetria & $-1,48$ & $-1,08$ & $-0,39$ & $-1,61$ & $-0,45$ \\
Curtose & 18,68 & 9,57 & 19,60 & 19,28 & 9,55 \\
Jarque-Bera & $<0,01$ & $<0,01$ & $<0,01$ & $<0,01$ & $<0,01$ \\
Coeficiente de variação & $-14,32$ & $-15,56$ & $-20,56$ & $-10,87$ & $-33,78$ \\
\hline
\end{tabular}

Nota. Fonte: Elaborado pelos autores.

A estatística descritiva dos prêmios das carteiras setoriais (Tabela 6) demonstra a presença de maior volatilidade dos retornos semanais por parte da carteira de materiais básicos $(\sigma=0,0487)$ seguida das de consumo cíclico $(\sigma=0,0358)$ e industrial $(\sigma=0,0348)$, o que faz sentido, na medida em que são setores mais sensíveis às oscilações no nível de atividade econômica (setores com maiores elasticidades preço e renda da demanda). Destaque também para a assimetria a direita dos retornos de todos os setores (característica comum no mercado de ações), mais acentuada nos de consumo não cíclico e utilidade pública. O teste de JarqueBera rejeita a hipótese nula de normalidade dos prêmios semanais para todas as carteiras setoriais.

\subsection{Regressões}

Nesta seção serão apresentados os parâmetros obtidos a partir de regressões estimadas pelo método SUR. O pacote econométrico utilizado para o processo de estimação foi o R Studio. Para correção dos estimados das regressões aplicou-se a matriz de covariância de Newey-West (matriz HAC).

Os resultados obtidos pelo método OLS não foram apresentados para poupar espaço e não fadigar o leitor (podendo ser enviados aos interessados). A comparação entre os resultados dos dois métodos de estimação demonstraram a redução dos erros-padrões obtida pelo método SUR, também refletida no $R^{2}$ ajustado empiricamente superior ao obtido por meio do método de OLS. 
A regressão da primeira carteira setorial, a de materiais básicos (Tabela 7), aponta o prêmio de mercado e o RMW como fatores estatisticamente significativos ao nível de significância de $1 \%$. Interessante notar a relevância da lucratividade ( $R M M)$ na precificação da carteira materiais básicos, um setor volátil em termos de resultados (uma variação negativa de $1 \%$ no $R M W$ provoca uma oscilação positiva de $0,44 \%$ no retorno da carteira de materiais básicos). Sua atividade concentra-se basicamente na circulação de commodities, com baixo valor agregado, dependente das cotações internacionais dessas matérias-primas e insumos, fator que impacta a lucratividade destas organizações. Operações de hedge nos mercados futuros são usualmente realizadas pelas tesourarias dessas companhias, uma tentativa de atenuar essa volatilidade. O intercepto significante a 5\% traz uma ressalva para aplicação do modelo nesse setor.

Tabela 7

\section{Regressão SUR Materiais Básicos}

\begin{tabular}{lcccc}
\hline & $R_{\mathrm{MB}, t}-R_{l r, t}=a_{i}+b_{i}\left(R_{M t}-R_{F t}\right)+S_{i} S M B_{t}+h_{i} H L_{t}+r_{i} R M W_{t}+c_{i} C M A_{t}+e_{i t}$ \\
\hline Variáveis & Coeficiente & Erro-Padrão & Estatística t & p-valor \\
\hline Intercepto & 0,00286 & 0,00123 & 2,57 & $0,0104^{* *}$ \\
Rm-Rf & 1,23896 & 0,04321 & 14,82 & $0,0000^{* * *}$ \\
SMB & $-0,09243$ & 0,07001 & $-0,68$ & 0,4938 \\
HML & 0,08706 & 0,09562 & 0,74 & 0,4567 \\
RMW & $-0,44131$ & 0,09671 & $-2,87$ & $0,0043^{* * *}$ \\
CMA & 0,22540 & 0,09008 & 1,27 & 0,2063 \\
\hline
\end{tabular}

Nota: $R^{2}$ ajustado $=0,7492$. Significância: ${ }^{* * *},{ }^{* *} \mathrm{e}^{*}$ correspondem a $0.01,0.05$ e 0.1 , respectivamente. Nota. Fonte: Elaborado pelos autores.

$\mathrm{Na}$ segunda carteira setorial, a de consumo cíclico (Tabela 8), os fatores estatisticamente significativos foram prêmio de mercado, RMW e CMA. Relevante destacar que para essa carteira, assim como na de consumo não cíclico, o intercepto foi estatisticamente significante a $1 \%$, trazendo uma ressalva para o modelo aplicado nesses setores, o que é contrastado pelo elevado $R^{2}$ ajustado dos respectivos modelos, $86,29 \%$ e $87,94 \%$, respectivamente.

Tabela 8

\section{Regressão SUR Consumo Cíclico}

\begin{tabular}{|c|c|c|c|c|}
\hline \multicolumn{5}{|c|}{$R_{\mathrm{CC}, t}-R_{l r, t}=a_{i}+b_{i}\left(R_{M t}-R_{F t}\right)+s_{i} S M B_{t}+h_{i} H M L_{t}+r_{i} R M W_{t}+c_{i} C M A_{t}+e_{i t}$} \\
\hline Variáveis & Coeficiente & Erro-Padrão & Estatística t & p-valor \\
\hline Intercepto & 0,00241 & 0,00066 & 3,40 & $0,0007^{* * *}$ \\
\hline $\mathrm{Rm}-\mathrm{Rf}$ & 1,02146 & 0,02344 & 31,44 & $0,0000^{* * *}$ \\
\hline SMB & 0,14476 & 0,03798 & 1,64 & 0,1026 \\
\hline HML & 0,08921 & 0,05187 & 1,15 & 0,2514 \\
\hline RMW & 0,20092 & 0,05246 & 2,18 & $0,0298^{* *}$ \\
\hline CMA & $-0,14537$ & 0,04886 & $-2,32$ & $0,0207^{* *}$ \\
\hline
\end{tabular}

Nota: $R^{2}$ ajustado $=0,8629$. Significância: ${ }^{* * *},{ }^{* *} \mathrm{e}^{*}$ correspondem a $0.01,0.05$ e 0.1 , respectivamente. Nota. Fonte: Elaborado pelos autores.

$\mathrm{Na}$ terceira carteira setorial, a de consumo não cíclico (Tabela 9), os fatores significantes foram prêmio de mercado, SMB e HML. Os coeficientes do SMB e HML mostram que uma pequena variação negativa dos retornos desses fatores $(-0,12 \%$ e $-0,18 \%)$ provoca uma variação positiva na carteira de consumo não cíclico (de $+1 \%$ ). 
Tabela 9

Regressão SUR Consumo Não Cíclico

\begin{tabular}{lllll}
\multicolumn{4}{l}{$R_{\mathrm{CNC}, t}-R_{l r, t}=a_{i}+b_{i}\left(R_{M t}-R_{F t}\right)+S_{i} S M B_{t}+h_{i} H M L_{t}+r_{i} R M W_{t}+c_{i} C M A_{t}+e_{i t}$} \\
\hline Variáveis & Coeficiente & Erro-Padrão & Estatística t & p-valor \\
\hline Intercepto & 0,00236 & 0,00057 & 4,17 & $0,0000^{\star * *}$ \\
Rm-Rf & 0,93951 & 0,02020 & 48,18 & $0,0000^{\star * *}$ \\
SMB & $-0,11829$ & 0,03272 & $-2,00$ & $0,0466^{\star *}$ \\
HML & $-0,18154$ & 0,04469 & $-3,44$ & $0,0006^{\star \star *}$ \\
RMW & 0,08087 & 0,04520 & $-1,04$ & 0,2957 \\
CMA & 0,07363 & 0,04210 & 1,27 & 0,2036 \\
\hline
\end{tabular}

Nota: $R^{2}$ ajustado $=0,8794$. Significância: ${ }^{* * *},{ }^{* *} \mathrm{e}^{*}$ correspondem a $0.01,0.05$ e 0.1 , respectivamente.

Nota. Fonte: Elaborado pelos autores.

$\mathrm{Na}$ quarta carteira setorial, a industrial (Tabela 10), os fatores relevantes foram prêmio de mercado e o CMA. O fator CMA significativo ressalta uma influência positiva da taxa de investimento nos retornos do setor industrial (uma variação de $0,24 \%$ no CMA provoca uma oscilação de $1 \%$ no retorno da carteira industrial). Essa relação faz sentido na medida em que o setor é formado por empresas com uma elevada posição de ativos, intensivas em capital, cuja principal atividade é a circulação de bens de capital, justificando a intensa sensibilidade dos prêmios da carteira industrial em relação à variação de ativos (CMA).

Tabela 10

Regressão SUR Industria

\begin{tabular}{|c|c|c|c|c|}
\hline Variáveis & Coeficiente & Erro-Padrão & Estatística t & p-valor \\
\hline Intercepto & 0,00138 & 0,00076 & 2,19 & $0,0287^{* *}$ \\
\hline Rm-Rf & 1,01778 & 0,02667 & 17,80 & $0,0000^{* * *}$ \\
\hline SMB & 0,07131 & 0,04321 & 0,90 & 0,3685 \\
\hline HML & $-0,03829$ & 0,05902 & $-0,59$ & 0,5558 \\
\hline RMW & 0,09663 & 0,05970 & 1,08 & 0,2797 \\
\hline CMA & 0,23623 & 0,05560 & 2,26 & $0,0242^{* *}$ \\
\hline
\end{tabular}

Nota: $R^{2}$ ajustado $=0,8135$. Significância: ${ }^{* * *},{ }^{* *} \mathrm{e}{ }^{*}$ correspondem a $0.01,0.05$ e 0.1 , respectivamente.

Nota. Fonte: Elaborado pelos autores.

$\mathrm{Na}$ quinta carteira setorial, a de utilidade pública (Tabela 11), os fatores significantes foram prêmio de mercado, $S M B$ e $C M A$. O fator $S M B$, significante a $1 \%$, tem uma relação inversa de $0,42 \%$ com o retorno da carteira utilidade pública. Esse comportamento tem uma explicação intuitiva, que decorre da estrutura de mercado do setor de utilidade pública pautada na presença de barreiras à entrada decorrente da regulação legal (inerente ao processo de concessão para exploração dos serviços de utilidade pública) e do processo de produção (presença de economias de escala), tornando-o próximo de uma estrutura monopolista. Essa característica reflete a influência do fator tamanho $(S M B)$ na precificação do setor de utilities.

Tabela 11

\section{Regressão SUR Utilidade Pública}

\begin{tabular}{lllll}
\hline$R_{\mathrm{UP}, t}-R_{l r, t}=a_{i}+b_{i}\left(R_{M t}-R_{F t}\right)+S_{i} S M B_{t}+h_{i} H M L_{t}+r_{i} R M W_{t}+c_{i} C M A_{t}+e_{i t}$ & \\
\hline Variáveis & Coeficiente & Erro-Padrão & Estatística t & p-valor \\
\hline Intercepto & 0,00132 & 0,0008 & 1,57 & $0,0922^{*}$ \\
Rm-Rf & 0,76510 & 0,0297 & 15,63 & $0,0000^{* * *}$ \\
SMB & $-0,42006$ & 0,0482 & $-7,03$ & $0,0000^{* * *}$ \\
HML & 0,09723 & 0,0658 & 1,37 & 0,1720 \\
RMW & 0,10862 & 0,0665 & 1,43 & 0,1531 \\
CMA & 0,25778 & 0,0620 & 2,57 & $0,0106^{* *}$ \\
\hline
\end{tabular}

Nota: $R^{2}$ ajustado $=0,6951$. Significância: ${ }^{* \star *},{ }^{* *} \mathrm{e}^{*}$ correspondem a $0.01,0.05$ e 0.1 , respectivamente.

Nota. Fonte: Elaborado pelos autores. 
O prêmio de mercado é estatisticamente relevante em todas as regressões estimadas, o que corrobora sua contribuição para a capacidade explicativa do modelo de 5-fatores, fortalecendo o beta de mercado como o componente mais relevante do modelo de precificação.

\section{CONCLUSÕES}

O presente trabalho utilizou os componentes do modelo de 5-fatores de risco proposto por Fama e French (2015a) para verificar suas respectivas influências nos retornos do mercado acionário brasileiro. A classe de ativos investigada foram os retornos semanais de carteiras setoriais.

Para obter os componentes do modelo de precificação foi utilizado o método de carteiras $2 \times 2 \times 2 \times 2$ que produziu oito portfolios, a partir do ordenamento com base nas variáveis inerentes aos fatores de risco (valor de mercado, B/M, EBIT/PL e variação do ativo). A ordenação foi realizada em quatro passos, produzindo em cada passo duas carteiras, obtidas por uma metodologia de corte que utiliza a mediana dos quatro fatores supracitados. Tendo os retornos semanais equally wheighted dessas carteiras, os fatores de risco são obtidos por meio de uma simples diferença de médias.

$\mathrm{Na}$ última etapa procedeu-se ao teste do modelo. O processo de estimação eleito foi o de regressões lineares múltiplas do tipo SUR. Os resultados apontam a importância do prêmio de mercado estatisticamente significativo para todos os cinco setores testados. Além da significância esperada desse prêmio, o prêmio de risco atrelado aos investimentos foi significante em três dos cinco setores da economia estudados. Isso evidencia a capacidade de explicação da quantidade de investimento em relação ao retorno das empresas. Esse fato em particular mostra aos gestores a importância em refletir sobre a política de investimento da organização, devido ao seu impacto no resultado.

Interessante notar nos resultados que nem sempre um aumento nos investimentos impacta positivamente a performance da empresa naquele momento, fato verificado no coeficiente negativo do setor de consumo cíclico, diferentemente dos setores Industrial e de Utilidade Pública, que tiveram coeficientes positivos.

A presença de interceptos significativos, ao nível de significância de 1\% para os setores de consumo (cíclico e não cíclico) e de $5 \%$ para os de materiais básicos e industrial, e de $10 \%$ para o de utilidade pública demonstra a existência de influências nos retornos dos prêmios das carteiras setoriais não captadas pelo modelo de 5-fatores.

Contrasta com esse resultado, como pontos favoráveis ao modelo de precificação, a baixa correlação entre os fatores de risco (afastando possíveis problemas de muticolinearidade) e o alto poder explicativo do modelo de fatores refletido nos $R^{2}$ ajustados das respectivas regressões.

Uma das limitações do estudo é o tamanho do mercado de ações brasileiro que dificulta a construção de carteiras diversificadas para períodos anteriores a 2008, antes do boom de IPO's, citado na seção 3.1. O número de empresas listadas e o baixo volume de negociação do mercado de ações também se refletem na dificuldade de implantação de outras metodologias para construção das carteiras. No seu estudo, Fama e French (2015a) montam carteiras $2 \times 4 \times 4$ (32 carteiras), $5 \times 5$ (25 carteiras), segmentando os portfolios a partir de quartis e quintis para controle das variáveis, por exemplo, técnicas de difícil replicação para o mercado brasileiro. Ressalta-se, portanto, a relevância de adaptar os modelos de precificação às condições do mercado de capitais investigado.

O processo de estimação também constitui uma limitação. Recomenda-se que pesquisas futuras façam uso de dados em painéis, a partir do emprego de séries temporais conjugadas com corte transversal. O emprego do teste estatístico GRS, adotado no estudo de Fama e French (2015a), pode ser uma técnica econométrica empregada para validar modelos de precificação que adotarem dados em painel como método de estimação. 


\section{REFERÊNCIAS}

Aharony, G., Grudy, B. \& Zeng, Q. (2013). Stock returns and the Miller Modigliani valuation formula: revisiting the Fama French analysis. Journal of Financial Economics, 110(2), 347-357.

Black, F, Jensen, C., \& Scholes, M. (1972). The capital asset pricing model: some empirical tests. Studies in the Theory of Capital Markets, Praeger Publishers Inc, 54 p.

Brooks, C. (2014). Introductory Econometrics for Finance (3rd. ed.). Cambridge University Press: New York, $740 \mathrm{p}$.

Caldeira, J, Moura, G., \& Santos, A (2013). Seleção de Carteiras Utilizando o Modelo. Revista Brasileira de Economia, 67(1), 45-65.

Carhart, M.M. (1997). On persistence in mutual fund performance. Journal of Finance, 52(1), 57-82.

Costa, N. da, Jr., \& Neves, M. (2000). Variáveis fundamentalistas e os retornos das ações. Revista Brasileira de Economia, 54(1), 123-137.

Damodaran, A. (2012). Investment Valuation: Tools and Techniques for Determining the Value of Any Asset (3rd. ed.) Wiley Finance, 992 p..

Duarte, P., Lamounier, W., \& Takamatsu, R. (2007). Modelos Econométricos para Dados em Painel: Aspectos Teóricos e Exemplos de Aplicação à Pesquisa em Contabilidade e Finanças. Anais do Congresso USP de Controladoria e Contabilidade, São Paulo, SP, 7.

Fama, E., \& French, K. (1992). The cross-section of expected stock returns. Journal of Finance, 47(2), 427-465

Fama, E., \& French, K. (1993). Common risk factors in the returns on stocks and bonds. Journal of Financial Economics, 33(1), 3-56.

Fama, E., \& French, K. (1995). Size and book-to-market factors in earnings and returns. Journal of Financial Economics, 50 (1), 131-155.

Fama, E., \& French, K. (2004). The Capital Asset Pricing Model: Theory and Evidence. Journal of Economic Perspectives, 18(3), 25- 46.

Fama, E., \& French, K. (2006). The Value Premium and the CAPM. Journal of Finance, 61(5), 2163-2185.

Fama, E., \& French, K. (2015a). A five-factor asset pricing model. Journal of Financial Economics, 116, 1-22.

Fama, E., \& French, K. (2015b). Dissecting Anomalies with a Five-Factor Model. Fama-Miller Working Paper, Tuck School of Business Working Paper No. 2503174.

Fama, E., \& French, K. (2015c). International Tests of a Five-Factor Asset Pricing Model. FamaMiller Working Paper, Tuck School of Business Working Paper No. 2622782.

Jegadeesh, N., \& Titman, S. (1993). Returns to buying winners and selling loosers: Implications for stock market efficiency. Journal of Finance, 48(1), 65-91.

Leite, A, Pinto, A., \& Klotzle, M. (2016). Efeitos da Volatilidade Idiossincrática na Precificação de Ativos. Revista Contabilidade \& Finanças, 27(70), 98-112.

Lintner, J. (1965). The valuation of risk assets and the selection of risky investments in stock portfolios and capital budgets. The Review of Economics and Statistics, 47(1), 13-37.

Markowitz, H. (1952). Portfolio selection. The Journal of Finance, 7(1), 77-91.

Mossin, J. (1966). Equilibrium in capital asset market. Econometrica, 34, 768-783.

Neves, M. (1996). Utilização do beta, índice $P / L$, valor de mercado e valor contábil na relação risco-retorno no mercado acionário brasileiro. Rio de Janeiro. Dissertação (Mestrado em Administração de Empresas). Universidade Federal do Rio de Janeiro - COPPEAD. 
Novy-Marx, R. (2012). Is momentum really momentum? Journal of Financial Economics, 103(3), 429-453.

Roll, R. (1977). A critique of the asset pricing theory's test: part I: on past and potential testability of the theory. Journal of Financial Economics, 4, 129-176.

Sharpe, W. F. (1964). Capital asset prices: a theory of market equilibrium under conditions of risk. Journal of Finance, 19, 425-443.

Stambaugh, R. (1982). On the Exclusion of Assets from Tests of the Two-Parameter Model: A Sensitivity Analysis, Journal of Financial Economics, 10 (3), 237-268. 